\title{
HIV/AIDS Treatment and Physicochemical Quality Control of Medicines: Evaluation of Non-Generic Lamivudine + Zidovudine Tablets Manufactured in Brazil
}

\author{
Ruy Carlos Ruver Beck, Margareth Linde Athayde and Simone Gonçalves Cardoso \\ Department of Pharmaceutical Industry, Center of Health Sciences, Federal University of Santa Maria (UFSM); Santa Maria, RS, Brazil
}

\begin{abstract}
In this work it was evaluated the physicochemical quality of lamivudine + zidovudine tablets, whose association belongs to the list of drugs distributed by the Brazil's National Program on Sexually Transmitted Diseases and AIDS. Four non-generic products (lamivudine + zidovudine tablets) were analyzed. They were obtained from different Brazilian manufacturers, besides a reference product. The quality was evaluated by physicochemical tests described in the official codes. A validated reversed-phase high performance liquid chromatography (HPLC) method was used for the assay of the active substances. All samples were in accordance to the requisites in relation to their physicochemical characteristics. Dissolution studies showed similar drug percentual dissolved among all samples. The results reflect the interest of the national pharmaceutical industry to ensure the delivery of safer and cheaper drugs to the Brazilian people, with particular importance in the National Program on Sexually Transmitted Diseases and AIDS.
\end{abstract}

Key-Words: Antiretroviral therapy, quality control, lamivudine, public health, tablets, zidovudine.

Since the discovery of acquired immunodeficiency syndrome (AIDS) in 1981, it has been obtained considerable progress in development of anti-HIV (human immunodeficiency virus) therapy. Nucleoside reverse transcriptase inhibitors (NRTIs) were the first class of drugs that were introduced as antiretroviral agents for the treatment of infection with HIV [1]. Zidovudine was the first chemical substance which showed an anti-HIV activity, in 1985 [2]. Combined antiretroviral therapy is preferentially adopted in relation to the monotherapy, as the first choice for the treatment of HIV-positive patients [2,3]. Lamivudine administered in association with zidovudine is an effective agent for the treatment of symptomatic as well as of asymptomatic patients [3]. After 1996, with the advent of highly active antiretroviral therapy (HAART), like protease inhibitors, and respective therapeutic protocols, a new course in the history of the HIV/ AIDS epidemic has been observed. In Brazil, some public policies targeting health services were created to guarantee the universal access of patients to HAART, which were decisive to decrease the morbimortality rates and increase the quality of live of HIV/AIDS patients [4-7].

Therapeutic use and commerce of tablets containing the association of lamivudine and zidovudine are well established in Brazil. They belong to the role of eight antiretroviral agents manufactured in Brazil. Among the priorities of the Brazil's National Program on Sexually Transmitted Diseases and AIDS are the amplification of the program coverage, the guarantee of the universal and free access to the antiretroviral treatment and the increase in the national capacity to manufacture this class of drugs $[8,9]$.

Received on 17 July 2007; revised 30 October 2007.

Address for correspondence: Prof. Dr. Ruy Carlos Ruver Beck. Departamento de Farmácia Industrial - Universidade Federal de Santa Maria (UFSM). Av. Roraima, 1000 - Prédio 26, 97105-900, Santa Maria, RS, Brazil. E-mail: ruybeck@smail.ufsm.br.

The Brazilian Journal of Infectious Diseases 2007;11(6):540-543. (C) 2007 by The Brazilian Journal of Infectious Diseases and Contexto Publishing. All rights reserved.
Marins and co-workers [10] showed in a specific study that the introduction of HAART in public health services seems to be the major responsible for the increase of life expectancy in people living with HIV/AIDS. In this way, in Brazil, many efforts have been made to improve the national manufacturing of antiretroviral drugs by official and/or national pharmaceutical laboratories. Today, $80 \%$ of the amount reserved to the acquisition of antiretroviral agents are destined to import expensive and patented medicaments, whereas only $20 \%$ are destined to the acquisition of national products [11]. These aspects become of high importance considering that the costs of antiretroviral medicaments can represent the most expensive item in the HIV treatment, reaching more than $80 \%$ of the total amount [12].

Considering that the quality of medicines manufactured in national and international pharmaceutical laboratories is intimately related to the success in the anti-HIV treatment (decrease in mortality rates, increase in quality of life of AIDS patients), the objective of this work was to evaluate the quality of four non-generic products (tablets) from different Brazilian laboratories, containing the association of lamivudine plus zidovudine $(150 \mathrm{mg}+300 \mathrm{mg})$. All the results were compared to a reference product. The study evaluated the physicochemical characteristics of the tablets directly related to their quality such as: mean weight, hardness, friability, disintegration time, identification, assay (lamivudine and zidovudine), uniformity of content, and dissolution test.

\section{Materials and Methods \\ Reagents and Solvents}

Chemical reference substances - lamivudine (3TC) and zidovudine (AZT) - were kindly supplied by Laboratório Cristália (São Paulo, Brazil). Four samples (B, C, D and E) of tablets containing lamivudine plus zidovudine $(150+300 \mathrm{mg})$ obtained from four different Brazilian manufacturers' laboratories have been analyzed, as well as the reference product (Biovir $\AA$, GlaxoSmithKline - sample A). All batches were in accordance to their expiration date. Methanol (HPLC 
grade), reagents and solvents of analytical grade (ammonium acetate, chloride acid, ammonium hydroxide and glacial acetic acid) were used as received.

\section{Physicochemical Analyses of Tablets}

Mean weight, friability, hardness and disintegration time were evaluated according to the methodologies described in the Brazilian Pharmacopoeia [13].

Assay, Uniformity of Content and Identification of Active Substances in Tablets

Quantitative analyses were carried out using high performance liquid chromatography (HPLC) with detection at $270 \mathrm{~nm}$, using as stationary phase a LiChrospher ${ }^{\circledR} 100$ (RP-18, 125 x 4 mm, $5 \mu \mathrm{m}$, Merck, Darmstadt, Germany). Mobile phase was composed by a mixture of methanol and acetate buffer $(60: 40 \mathrm{v} / \mathrm{v}), \mathrm{pH} 6.5$, at a flow rate of $1.0 \mathrm{~mL}^{\mathrm{min}}{ }^{-1}$. The chromatographic system was validated according to the following parameters: linearity, accuracy, precision, specificity and concentration range [14]. The equipment was constituted by two Shimadzu LC-10AD pumps, UV/VIS SPD 10AD detector and a Shimadzu auto sampler (Shimadzu, Tokyo, Japan). Chromatograms were obtained and analyzed by Class-VP ${ }^{\circledR}$ software (Shimadzu, Tokyo, Japan).

\section{Preparation of Sample Solutions}

For the assay, initially, the mean weight of 20 tablets was determined, which were comminuted to a fine powder. An aliquot equivalent to 150 and $300 \mathrm{mg}$ of 3TC and AZT, respectively, was transferred to a $200 \mathrm{~mL}$ volumetric flask with $100 \mathrm{~mL} \mathrm{HCl} \mathrm{0.1} \mathrm{M.} \mathrm{The} \mathrm{samples}(\mathrm{n}=3)$ were mechanically agitated for 20 minutes. The volume of the volumetric flask was adjusted to $200 \mathrm{~mL}$ with $\mathrm{HCl} 0.1 \mathrm{M}$. Samples were centrifuged and the supernatant diluted to obtain a final concentration of 30.0 and $60.0 \mu \mathrm{g} \cdot \mathrm{mL}^{-1}$, for 3TC e AZT, respectively [14]. For the evaluation of uniformity of content, 10 tablets were individuality transferred to 10 different $200 \mathrm{~mL}$ volumetric flasks and submitted to the same process as described above for the assay. All the solutions were filtered $(0.45 \mu \mathrm{m})$ before injected in HPLC system.

\section{Preparation of Chemical Reference Substances Solutions}

Seventy-five $\mathrm{mg}$ of $3 \mathrm{TC}$ and $150.0 \mathrm{mg}$ of AZT were accurately weighed and transferred to a $100 \mathrm{~mL}$ volumetric flask. After solubilizing the reference chemical substances in the mobile phase, the volume of volumetric flask was adjusted to $100 \mathrm{~mL}$ and the sample was appropriately diluted to final concentrations of 30.0 and $60.0 \mu \mathrm{g} . \mathrm{mL}^{-1}$ of $3 \mathrm{TC}$ and AZT, respectively [14]. All the solutions were filtered $(0.45 \mu \mathrm{m})$ before injected in HPLC system.

Identification of the active substances (3TC and AZT) was carried out by comparison between the retention time of the chromatographic peaks from each sample solution and its respective chemical reference solution [14].

\section{Dissolution Test}

Dissolution test was carried out using as a dissolution medium $900 \mathrm{~mL}$ of distilled water, at $37 \pm 0.5^{\circ} \mathrm{C}$ (Pharma Test PTWII, Hamburg, Germany). After the immersion of the tablets, the agitation was done by paddle at $50 \mathrm{rpm}$, during 30 minutes [15]. After the specific time, samples of $20.0 \mathrm{~mL}$ were collected from each vessel $(n=6)$ and centrifuged. These supernatants were adequately diluted to obtain a concentration of 30.0 and $60.0 \mu \mathrm{g} . \mathrm{mL}^{-1}$ of 3TC and AZT, respectively. The samples were filtered $(0.45 \mu \mathrm{m})$ and analyzed by HPLC, according to the methodology previously described. Although Brazilian Pharmacopoeia [13] recommends the evaluation of additional stages of some samples, which would be not in accordance to the current specifications, in this work we evaluated the dissolution time in only one stage because of the high cost of the medicines used as samples.

\section{Results and Discussion}

Considering the great importance of the national medicines for the public policies of free distribution of medicines used in the treatment of AIDS, maintained by the Brazilian Ministry of Health, and their important contribution to decrease the costs of these programs, it was carried out a comparative study of the physicochemical quality of some non-generic products (tablets) available in the Brazilian national market, containing the association of lamivudine and zidovudine $(150+300 \mathrm{mg})$. Four samples provided by different national laboratories were analyzed, according to the pharmacopeial requirements and the results compared to the reference product (Biovir $₫$, GlaxoSmithKline).

Initially, it was evaluated the physicochemical characteristics of the tablets. Table 1 shows the data from mean weight, hardness, friability and disintegration time. Mean weight, obtained from individual weights of 20 tablets, gives information about the variations in weight in tablets of the same batch, being one of the parameters which could influence the active uniformity of content among different tablets [16]. Hardness and friability tests evaluate the resistance of tablets to crushing and to friction, respectively [16]. According to the Brazilian Pharmacopoeia [13], tablets should have a minimal hardness of $30 \mathrm{~N}$ and maximum friability of $1.5 \%$. Adequate values are necessary to guarantee that the tablets will remain intact during the manufacture, packing and transport process, as well as at the drug administration moment [16]. Determination of disintegration time evaluate the time necessary for the fragmentation of tablets in smaller granules, being a method that can predict the solubilization rate of active substances (dissolution rate), which become available to organism absorption [16]. All samples presented a weight variation below $5 \%$, hardness ranged between 47 and $222 \mathrm{~N}$, meeting pharmacopeial specification $(30 \mathrm{~N})$. In the friability test, the tablet samples showed a loss of powder lower than $0.5 \%$ in compliance to the specification (max. $1.5 \%$ ). All samples presented a disintegration time (7-12 min) lower than $30 \mathrm{~min}$ [13]. Therefore, the results presented in Table 1 showed that 
Table 1. Mean weight, hardness, friability and disintegration time of 3TC and AZT tablets $(150+300 \mathrm{mg})$ from 5 different manufacturers (A, B, C, D and E)

\begin{tabular}{ccccc}
\hline Product & $\begin{array}{c}\text { Mean weight }(\mathbf{m g}) \\
\text { Mean } \pm \text { SD }(\mathbf{N}=\mathbf{2 0}) \\
\text { (Weight variation) }\end{array}$ & $\begin{array}{c}\text { Hardness (N) } \\
\text { Mean } \pm \text { SD }(\mathbf{N}=\mathbf{6})\end{array}$ & $\begin{array}{c}\text { Friability (\%) } \\
(\mathbf{N}=\mathbf{2 0})\end{array}$ & $\begin{array}{c}\text { Desintegration } \\
\text { time (min) }(\mathbf{N}=\mathbf{6})\end{array}$ \\
\hline A & $760 \pm 6(751-774)$ & $222 \pm 31$ & 0.20 & 3 \\
B & $834 \pm 7(822-848)$ & $107 \pm 33$ & 0.08 & 3 \\
C & $755 \pm 10(739-780)$ & $148 \pm 17$ & 0.35 & 5 \\
D & $703 \pm 19(690-729)$ & $118 \pm 31$ & 0.01 & 7 \\
E & $750 \pm 19(707-787)$ & $47 \pm 37$ & 0.23 & 1 \\
Limits & Mean weight $\pm 5 \%$ & Min. 30 N & Max. 1.5\% & Max. 30 min \\
\hline
\end{tabular}

all evaluated products, including the reference product, were in accordance to the official specifications. These results are a guarantee that the tablets remain intact during all production stages. Moreover, they do not show any indicators of variability in active substances among different dosage units, indicated by the low mean weight variation.

In sequence, it has been assayed the active substances (lamivudine and zidovudine) and determined the uniformity of content in the tablet samples. The results of drug assay and uniformity of content are presented in Table 2. The drug assay is a test to compare the theoretical quantitative contents of active substances in dosage forms (declared value) to the real values, determined experimentally by their quantification using well established and validated methods. The analysis of the uniformity of content evaluates the drug dose variation among each unitary dosage form.

Regarding the evaluation of the samples assay and its relation to the respective chemical reference substances, all products showed a drug content between $90 \%$ and $110 \%$ of the declared value for both active substances. These values are within the acceptable limits established by most of the official codes. However, using a statistical variance analyses (ANOVA, $\mathrm{p} \leq 0.05$ ), it could be showed a difference in drug content among all products, excepting samples $\mathrm{C}$ and $\mathrm{D}$, which were considered statistically similar. In relation to the uniformity of content test (Table 2), all samples met the general specification for tablets $(85 \%-115 \%, \mathrm{RSD} \leq 6.0 \%)$ [13]. Moreover, by the chromatographic methods used for active substances assay it was possible to attest the identities of lamivudine and zidovudine, comparing the retention times among chemical reference substances and the different tablet samples (3TC: $2.37 \mathrm{~min}$; AZT: $3.31 \mathrm{~min}$ ).

In Table 3, the results obtained in the dissolution test using distilled water as medium are shown [15]. This test evaluates, among other factors, the rate in which the drug substances become soluble and available to be absorbed by the human body [16]. From the dissolution test results (Table 3), it can be observed that all samples showed a mean release higher than $85 \%$ after 30 minutes. However, according to the general specifications from the Brazilian Pharmacopoeia [13], this mean is not the only factor to be considered in the analyses of the results obtained from a dissolution test of solid dosage forms. The individual behavior of each unit must be considered. Since there is no official monography to establish the mean percentual release from lamivudine + zidovudine tablets, we carried out only the comparison of the means after 30 minutes. Statistical analysis (ANOVA, $\mathrm{p} \leq 0.05$ ) showed no difference of the mean percentual release among all tested samples (A, B, C, D and E), considering both drug substances (3TC and AZT), confirming the results observed in the physicochemical tests, showing that any tested product (A, B, C, D and E) present a quality deviation.

\section{Conclusion}

The results obtained in this comparative study of the physicochemical quality of lamivudine + zidovudine tablets manufactured in Brazil demonstrated that all products met the requirements in relation to the mean weight, hardness, friability, disintegration time, assay, drug identification and uniformity of content, being comparable to the reference product. The dissolution test showed mean percentual release results higher than $85 \%$ of both drug substances for all samples. The results reflect the interest of the national pharmaceutical industry to ensure the delivery of safer and cheaper drugs to the Brazilian people, with particular importance in the National Program on Sexually Transmitted Diseases and AIDS. Although it was not showed quality deviation of the tested products in this work, it must be emphasized the importance of this kind of study, as a scientific mean to divulge information about the quality of medicines distributed by the official public health programs. Specifically in the case of antiretroviral medicines, it would be considered that the guarantee of the quality of them is closely related to the decrease in the morbimortality rates, besides the aspects of adhesion and free access to therapy. Although the set of data obtained in this study demonstrated that all samples met the general physicochemical quality parameters for tablets, equivalence and bioequivalence studies must be carried out to attest the interchangeability of these products. 
Table 2. Assay $(n=3)$ and uniformity of content $(n=10)$ of 3 TC and AZT tablets $(150+300 \mathrm{mg})$ from 5 different manufacturers $(\mathrm{A}, \mathrm{B}, \mathrm{C}, \mathrm{D}$ and $\mathrm{E})$

\begin{tabular}{|c|c|c|c|c|c|}
\hline \multirow[t]{2}{*}{ Product } & & \multirow{2}{*}{$\begin{array}{c}\text { Assay (\%) } \\
(n=3)\end{array}$} & \multicolumn{3}{|c|}{ Uniformity of content $(\%)(\mathrm{N}=10)$} \\
\hline & & & Lower & Higher & $\mathbf{R S D}(\%)$ \\
\hline \multirow[t]{2}{*}{ A } & $3 \mathrm{TC}$ & $96.52 \pm 0.12^{\mathrm{d}}$ & 95.05 & 100.90 & 1.85 \\
\hline & $\mathrm{AZT}$ & $96.42 \pm 0.14^{\mathrm{C}}$ & 96.50 & 101.70 & 1.69 \\
\hline \multirow[t]{2}{*}{ B } & 3TC & $95.41 \pm 0.09^{c}$ & 96.88 & 102.09 & 1.72 \\
\hline & AZT & $98.57 \pm 0.17^{\mathrm{E}}$ & 100.40 & 104.31 & 1.30 \\
\hline \multirow[t]{2}{*}{$\mathrm{C}$} & 3TC & $93.26 \pm 0.10^{b}$ & 92.52 & 102.49 & 3.10 \\
\hline & $\mathrm{AZT}$ & $95.96 \pm 0.11^{\mathrm{B}}$ & 94.29 & 101.23 & 2.45 \\
\hline \multirow[t]{2}{*}{$\mathrm{D}$} & 3TC & $93.43 \pm 0.10^{b}$ & 91.51 & 102.82 & 4.06 \\
\hline & $\mathrm{AZT}$ & $97.18 \pm 0.11^{\mathrm{D}}$ & 93.45 & 106.04 & 3.94 \\
\hline \multirow{3}{*}{$\mathrm{E}$} & 3TC & $90.00 \pm 0.06^{\mathrm{a}}$ & 90.26 & 97.30 & 2.63 \\
\hline & $\mathrm{AZT}$ & $92.38 \pm 0.23^{\mathrm{A}}$ & 93.12 & 101.03 & 2.50 \\
\hline & Limits & $90-110 \%$ & $85-115 \%$ & \multicolumn{2}{|c|}{$\leq 6.00$} \\
\hline
\end{tabular}

Means, in column, with different letters are statistically different (ANOVA, Tukey test, $\mathrm{p} \leq 0.05$ ).

Table 3. Lamivudine and zidovudine percent released (\%) from tablets (3TC + AZT, $150+300 \mathrm{mg})$ provided by 5 different manufacturers (A, B, C, D and E), using distilled water as dissolution medium

\begin{tabular}{ccccc}
\hline \multirow{2}{*}{ Product } & & \multicolumn{3}{c}{ Mean percent released $(\%)(\mathbf{N}=6)$} \\
\cline { 3 - 5 } & & Lower & Higher & Mean \\
\hline \multirow{2}{*}{ A } & 3TC & 89.64 & 101.43 & $95.29 \pm 4.41$ \\
& AZT & 87.09 & 93.57 & $90.02 \pm 2.48$ \\
B & 3TC & 94.13 & 104.50 & $97.38 \pm 4.01$ \\
& AZT & 91.72 & 97.96 & $95.61 \pm 3.75$ \\
C & 3TC & 91.64 & 98.75 & $95.03 \pm 3.05$ \\
& AZT & 87.72 & 95.81 & $91.55 \pm 3.47$ \\
D & 3TC & 87.93 & 106.41 & $95.42 \pm 6.86$ \\
& AZT & 84.50 & 96.89 & $89.94 \pm 5.14$ \\
E & 3TC & 84.71 & 95.03 & $90.81 \pm 4.70$ \\
& AZT & 83.79 & 91.95 & $88.90 \pm 3.91$ \\
\hline
\end{tabular}

\section{References}

1. Verweij-Van Wissenab C.P.W.G.M., Aarnoutse R.E., Burger DM. Simultaneous determination of the HIV nucleoside analogue reverse transcriptase inhibitors lamivudine, didanosine, stavudine, zidovudine and abacavir in human plasma by reversed phase high performance liquid chromatography. J Chromatogr B 2005;816:121-9.

2. De Souza M.V.N. Fármacos Inibidores de Fusão: uma Nova Estratégia no Combate à Replicação do Vírus HIV. Acta Farm. Bonaerense 2005;24:291-9.

3. Perry C.M., Faulds D. Lamivudine - A review of its antiviral activity, pharmacokinetic properties and therapeutic efficacy in the management of HIV infection. Drugs 1997;53:657-80.

4. Mocroft A., Gatell J., Reiss P., et al. Causes of death in HIV infection: the key determinant to define the clinical response to anti-HIV therapy. AIDS 2004;18:2333-7.

5. Teixeira P.R., Vitoria M.A., Barcarolo J. Antiretroviral treatment in resource-poor settings: the Brazilian experience. AIDS 2004;18 Suppl 3:S5-7.

6. Melo A.C., Caiaffa W.T., Cesar C.C., et al. Utilização de serviços de referência para o HIV/AIDS: comparando pacientes usuários e não usuários de drogas injetáveis. Cad Saúde Pública 2006;22:803-13.

7. Vlahov D., Celentano D.D. Access to highly active antiretroviral therapy for injection drug users: adherence, resistance, and death. Cad Saúde Pública 2006;22:705-18.
8. Brasil, Ministério da Saúde. Programa Nacional de DST e AIDS. http:// ww.aids.gov.br (acessado em 28/ago/2006).

9. Silveira M.P.T, Draschler M. L., Leite J. C. C. et al. Predictors of Undetectable Plasma Viral Load in HIV-Positive Adults Receiving Antiretroviral Therapy in Southern Brazil. BJID 2002;6:164-71.

10. Marins J.R.P., Jamal L.F., Chen S., et al. Sobrevivênvia atual dos pacientes com AIDS no Brasil. Evidência dos resultados de um esforço nacional. Boletim Epidemiológico da AIDS 2000.

11. Brasil, Ministério da Saúde. A sustentabilidade do acesso universal a anti-retrovirais no Brasil. $157^{\circ}$ Reunião Ordinária do Conselho Nacional de Saúde, 10/08/05. http://www.aids.gov.br; acessada em 28/ago/2006.

12. Monteiro M.G.S., Sudo E.C., Marques R.F.O., Mota D. M. Custos Envolvidos no Tratamento de Crianças Infectadas pelo HIV/aids no Município de São Luís. Acta Farm. Bonaerense 2004; 23:533-9.

13. Farmacopéia Brasileira. 4a ed. São Paulo, BR: Atheneu; 1988.

14. Beck R.C.R., Cardoso S.G, Athayde M.L., et al. Validação de método por cromatografia líquida de alta eficiência para determinação da lamivudina e zidovudina em comprimidos. Quim Nova 2007;30:1225-8.

15. Fernandes C, Junqueira R.G., Campos L.M.M., Pianetti G.A. Dissolution test for lamivudine tablets: Optimization and statistical analysis. J Pharmaceut Biomed 2006;42:601-6.

16. Alderborn G. Comprimidos e compressão. In: Aulton, ME, editor. Comprimidos e compressão. São Paulo: Artmed Editora, 2005. 